marks. In examining the shore of Hobson's Bay, Victoria, between Brighton and Mordiallac, I found recent shells in a ferruginous rock several feet above high-water mark, and exposed for more than a mile along the shore. This formation then gave place to a deposit of the same species of shells in a black sandy soil of the same character as those matrices mentioned as occurring here. I am thus able to add my humble testimony to the truth of the statements made by those geologists mentioned by Mr. Howorth. Not only do Tasmanian post-pliocene marine deposits find their analogues in New South Wales, Victoria, and other parts of the Australian mainland, but also the Miocene territory formations have their representatives there. For instance; at the East coast of this island seventy miles distant from Hobart Town, exist some very fine Miocene shell beds reposing on Silurian strata. These beds have their analogues in Victoria, at Schnapper point, where they also repose on Silurian strata. Again the somewhat celebrated Travertin deposit on the eastern bank of the Derwent, mentioned by Mr. Darvin, is completely represented at Geelong in that colony. I mention these last somewhat irrelevant features to show the analogy of physical conditions which existed in distant parts of Australasia from the middle Tertiary epoch down to the post-pliocene.

The oscillation of the land towards the Polar Regions is a question that demands strict and patient inquiry. That such a mutation is going on in this part of the globe, every intelligent geological observer is conscious of, and that at a computed rate of ten feet in the century. This is a fact which involves a variety of considerations with respect to past geological operations, and the popular theories propounded to explain them.

Although the land in this part of the globe is rapidly rising as well as according to published observations, that, in the Arctic regions, still $\mathrm{I}$ am in a position to show that an opposite movement took place during the close of the Tertiary or the dawn of the Pleistocene epochs by a sinking of certain tracts of land whereby Tasmania and New Zealand were isolated from the Australian mainland. I cannot do more at the present time than allude en passant to the important fact, and which must form the subject of a future communication.

Since writing the above I have examined a raised beach in the district of Sorrel, of many hundreds of acres in extent, composed of shells, having a mean thickness of five feet. The deposit is overgrown with trees and scrub. The trees are chiefly the Casuarina, or she-oak of the colonists, and it evidently flourishes on a soil of little else than shells. Although years ago lime burning was carried on for some years, so enormous is the deposit that there is scarcely a perceptible diminution.

Hobart Town, Oct. I

S. H. WINTLE

\section{THE COLOURED STARS ABOUT KAPPA CRUCIS}

M R. H. C. RUSSELL, of the Sydney Observatory, $\mathrm{NI}$ sends us an account of some observations he has recently made on the above small but beautiful cluster of stars. He believes his researches probably point it out as one of the stations from which astronomers will gatn fresh knowledge of the starry heavens. He gives a history of the cluster from its first recorded observation by Lacaille in 1750 . Dunlop, about 1828 , puts two stars in the place now occupied by $\phi$, which has considerably altered its place since Herschel made his map in 1835 . The star No. 87, Dunlop does not represent at, all, and says nothing of colour, though fond of recording coloured stars. In 1835 Herschel wrote a monograph on Kappa Crucis, and placed all the stars (I IO) on his map, but saw no nebulous light. Abbott of Tasmania, in r862, laid down 75 stars, and noted colours, remarking that certain changes were apparently taking place in the number, position, and colour of the component stars of the cluster. Nothing has been done since Abbott, till Mr. Russell determined to test for himself the latter's statement. He made a catalogue of all the stars (I30) seen with the Sydney equatorial, a coloured map showing all the stars, and notes. His map takes in as much space as Herschel's, but is four times as large. A close inspection shows a great many changes since Herschel observed, of which the most conspicuous of all is in the change between the present and past position of three stars, Nos. II, 2r, and 28, which have all moved from 4 to 6 seconds; and the star $\phi$ has also moved half a second in an opposite direction, and come nearly, but not quite, in a straight line with $\delta$ and $\epsilon$, which line, if produced, passes, not through $\zeta$, as in Abbott's observations, but half way between $\gamma$ and $\zeta$ Considerable change has also taken place in Nos. 1oo, I06, I20, 122, I26, and some others; and it is remarkable that the changes in the south preceding line are nearly all in R. A., while in those near $\beta$ and in the following side they are in declination, as if the cluster were made up of three sets of stars, two of which drift from the third in different directions. Five of Herschel's stars he could not see, but found 25 Herschel did not see; stars which, though all small, are yet in most cases brighter than some of those which Herschel recognised, and if there when Herschel examined, the cluster would not have been omitted; they are all well within the limits of his map, and several in parts of it which must have been most carefully examined. Two of them are near $a$, one near the string of stars south following it, one between $\beta$ and $\delta$, and two in the triangle 50s. after $a$, where Herschel shows 3 stars; of the others 5 precede $\alpha$ from is to $25 \mathrm{~s}$, 5 follow it from I 5 to $25 \mathrm{~s}$. and on the south side; 8 are on the north following side, and $\mathrm{I}$ cn the south following. Their numbers in my list are $2,3,4,6,7,15,19,31,60,69,73$, $76,79,86$, I10, I16, I17, I20, 123, 124, 125, 127, I28, I 29 , and I30. In Mr. Russell's list there are 24 stars about the roth magnitude, while in Herschel's there are only 7 ; and the mean magnitude of Herschel's 130 is 13 , while the mean of Russell's I 30 is I2.

These facts prove beyond all question, Mr. Russell thinks, that from some cause there has, as in the nebula of $\eta$ Argus, been here a considerable increase in brilliancy.

Mr. Russell thinks that we must either give up analogy, our safest guide, in such reasoning, or admit the gradual extinction of light in its passage through space, with its millions of meteor streams cutting the ecliptic at all angles, its thousands of comets, its meteoric dust, its zodiacal light, its solar corona, its material atmosphere, so to speak, occupying not only all the interplanetary space, but more or less to the limit of the sun's attractive force.

"And if we are to take our sun as a type of other suns, and in the mind's eye see all surrounded by such an atmosphere, and people all the interspaces with myriads of myriads of comets-nay more, if we accept the view held to be most probable by many astronomers, that it is by the deposition of this material atmosphere on the sun and planets that they are hourly growing and finding those stores of light and heat by which all things live, it is beyond question that there must have been a time when this material atmosphere was far more dense than it is at the present moment, and that there must be in every direction other suns in all stages of the process from the great nebulosity ' without form and void', to the Finished Sun, whatever that may be ; or, in other words, amidst the infinitude of such systems with which we are surrounded, there are places.where probably a sensible amount of clearing up has taken place within the last 35 years.

"And I think in this view we find a rational explanation of the appearance of new stars in this cluster, more especially since it has been shown by others, as well as 
myself, that in this region of the heavens about the remarkable star $\eta$ Argus, strange clearings up, so to speak, or wanings of nebulous light have taken place, and many stars have come to view, with telescopes far inferior to Herschel's.

"And whether we admit this view or not, one thing is absolutely certain. Under such a material atmosphere we live and make our observations, and we are not yet prepared to say with certainty whether there may not be such changes going on in it as will suffice for a full explanation of the appearance of these small stars, if not of the great changes about $\eta$ Argus."

\section{NOTES}

THE omission of a word in a note last week referring to the medals recently granted by foreign Governments to E nglishmen, makes this journal appear to hold the opinion that it is to be desired that the British Government should thus signalise British work. Such, however, is most emphatically not our opinion. What we do hold is that if foreign Governments reward Englis h work, it would be a graceful act for our Government from time to time to reciprocate such acts of international courtesy and good-will by marking in a similar manner its appreciation of foretgn work.

IN the Russian Official Gazette is an announcement that a diploma of honour has been conferred upon Baron Liebig for the application of his knowledge of theoretical chemistry to practical purposes.

THE morning of Saturday the 2rst has been fixed for the final despatch of H.M.S. Challenger on her long voyage. Her scientific staff-officers and civilians-are all on board, and the ship is busy from end to end, stowing and arranging her unwonted gear. As might be supposed, every available space is filled with books. Mr. Macmillan has received the thanks of the captain and officers and the civilian scientific staff, through Dr. Wyville Thomson, for a case of about fifty volumes of his newest publications, which he sent down as a parting gift.

Prof. Huxley has been elected Lord Rector of the University of Aberdeen, by a considerable majority over the Marquis of Huntly, a satisfactory evidence of the estimation in which eminence in science is held by the younger minds in Scotland.

WE regret to learn that $M$. Pouchet, of Rouen, celebrated as a leading champion of the doctrine of spontaneous generation, died in Paris on December 6.

THE following are the probable arrangements for the Friday evening meetings at the Royal Institution before Easter, 1873 :Jan. 17 , On the Old and New Laboratories at the Royal Institution, by W. Spottiswoode, F.R.S. ; Jan. 24, On the Analogies of Physical and Moral Science, by Rev. Prof. T. R. Birks; Jan $3 \mathrm{r}$, On the Music of the Future, by E. Dannreuther; Feb. 7 , On Old Continents, by Prof. A. C. Ramsay, F.R.S. ; Feb. I4, On Recent Progress in Weather Knowledge, by R. H. Scott, F.R.S. ; Feb. 2I, On Action at a Distance, by Prof. J. Clerk Maxwell, F.R.8. ; Feb. 28, On Livingstone's Explorations in Africa, by Sir H. C. Rawlinson, F.R.S.; March 7, On the Temperature of the Sun and the Work of Sunlight, by J. Dewar; March I4, On Steamers for Channel Communication, by E. J. Reed; March 2x, On New Alcohols from Flint, by J. Emerson Reynolds ; March 28, On the Meaning of Force and E'nergy, by Prof. W. K. Clifford; April 4, Prof. Tyndall, F.R.S.

NATURAL Science at Rugby is producing its fruits. In the recent examination for honours at Oxford, six men were placed in the first class; and of these, four were educated at RugbyMessrs. Baynes, Cleminshaw, Longstaff, and Lupton.

Dr. Harry Rainy, Emeritus Professor of Forensic Medicine in the University of Glasgow, has given a donation of $1,500 \%$ to the University for the endowment of bursaries, to be competed for by stüdents of Medicine.

DR. JoHn STEnhouse is at present investigating the higher iodo-derivatives of the orcines.

THE Riberi triennial prize of 20,000 lire $(800 \%$.) has been awarded to Dr. Guiseppe Corradi, director of the surgical clinic at Florence, for four works on the diseases of genito-urinary organs.

AT the second meeting of the North British Branch of the Pharmaceutical Society of Great Britain Prof. Crum Brown gave an address on the relation of the science of chemistry to the art of pharmacy. He afterwards sketched the career of Scheele, the Swedish chemist and druggist, who had contributed a large list of facts to science.

Prof. Freire-MARreco of Newcastle, and Mr. G. A. Lebour will lecture on January 8 , and February 5,1873 , at the Rothbury Reading Room, on Artificial Lighting and on Caverns.

A VERY important paper has been printed by Government, respecting the Phylloxera vastatrix, or new Vine Scourge. It commences with a letter from Sir C. Murray, H.M. Ambassador at Lisbon, calling attention to the ravages of the disease ; and stating that the Portuguese Government has named a Commission "to examine into the progress of this dangerous evil, and to gather from all quarters, whether scientific or practical (sic) suggestions for the best mode of extirpating it." A report follows from Mr. Crawford, H.M. Consul at Oporto, on the scientific aspects of the disease, as well as several others from French authorities, including a very important one addressed to the Minister of Agriculture and Commerce by the Commission instituted for the study of the new disease, M. Dumas, president. The various papers having been referred to Dr. Hooker for him to report upon them, he states that the only really effectual remedy at present discovered, and this can obvlously be only very partially applied, and not in the best districts, is flooding the vineyards in winter. $\mathrm{He}$ adds "there is reason to believe that on the first symptoms of attack in isolated cases, the prompt destruction of the vine, its burning on the spot, and the subsequent treatment of the soil with some approved insecticide, such as carbolic acid, would be of great importance." Vines of American species appear at present to have enjoyed immunity from its ravages in the Rhone district, but the disease has undoubtedly appeared in this country on vines cultivated under glass.

THE South London Entomological Society, which, though only nine months old, has been extremely successful, held on Thursday evening last, at Dunn's Institute, Newington Causeway, a very interesting exhibition of collections of insects, chiefly British Lepidoptera. The collections were made by the members themselves, all amateurs, and do them the greatest credit. The room was densely crowded, and the exhibition was a great success.

A society has been formed under the title of the National Health Society, which is to have for its object to help every man and woman, rich and poor, to know for himself, and to carry out practically around him, the best conditions of healthy living. The steps at present proposed are the holding of monthly meetings for the reading of papers ; the establishing of classes for instruction in various branches of sanitary science; the delivery of free popular lectures; and the formation of a reference library and an information office. 